\title{
Mammalian distal humeri from the Late Cretaceous of Uzbekistan
}

Stephen G.B. Chester, Eric J. Sargis, Frederick S. Szalay, J. David Archibald, and Alexander O. Averianov

Acta Palaeontologica Polonica 55 (2), 2010: 199-211 doi: http://dx.doi.org/10.4202/app.2009.0023

We describe mammalian distal humeri recovered from the Bissekty Formation, Dzharakuduk, Kyzylkum Desert, Uzbekistan (90 Ma). Isolated elements were sorted into groups that likely correspond to species (or genera). These groups were allocated to taxa known mostly from the dentition, petrosals, and/or tarsals at this site. We identified one humerus of a multituberculate and one of a zalambdalestid. Several eutherian humeri have been tentatively assigned to Zhelestidae based on their dissimilarity to zalambdalestids and the abundance of zhelestids in the dental record. The zalambdalestids and zhelestids were probably terrestrial. At least two metatherian taxa have also been identified, and both were likely arboreal. Although the dental record suggests twelve eutherian species and only one metatherian, crurotarsal evidence supports the presence of at least four metatherian species at Dzharakuduk. The humeri analyzed here also provide support for the presence of multiple metatherians in the fauna, further demonstrating that postcrania are critical to understanding the taxonomic diversity present at these Late Cretaceous localities.

Key words: Mammalia, Multituberculata, Metatheria, Zalambdalestidae, Zhelestidae, humerus, Cretaceous, Uzbekistan.

Stephen G. B. Chester [stephen.chester@yale.edu], Department of Anthropology, Yale University, P.O. Box 208277, New Haven, CT 06520; Eric J. Sargis [eric.sargis@ yale.edu ], Department of Anthropology, Yale University, P.O. Box 208277, New Haven, CT 06520; Division of Vertebrate Zoology, Peabody Museum of Natural History, New Haven, CT 06520; 2 Frederick S. Szalay [fszalay@unm.edu], Department of Biology, University of New Mexico, Albuquerque, NM 87131; J. David Archibald [darchibald@ sunstroke.sdsu.edu], Department of Biology, San Diego State University, 5500 Campanile Dr., San Diego, CA 92182; Alexander O. Averianov [sasha@AA1923.spb.edu], Zoological Institute, Russian Academy of Sciences, Universitetskaya nab. 1, St. Petersburg 199034, Russia. 
Attribution License (for details please see creativecommons.org), which permits unrestricted use, distribution, and reproduction in any medium, provided the original author and source are credited.

PoFif Full text $(822.6 \mathrm{kB})$ 